\title{
Conversion of 1,2-Propylene Glycol on Rutile $\mathrm{TiO}_{2}(110)$
}

\author{
Long Chen, Zhenjun Li, ${ }^{\dagger}$ R. Scott Smith, Bruce D. Kay, Zdenek Dohnálek*
}

Fundamental and Computational Sciences Directorate and Institute for Integrated Catalysis,

Pacific Northwest National Laboratory, P.O. Box 999, Mail Stop K8-88, Richland, Washington

99352, United States 


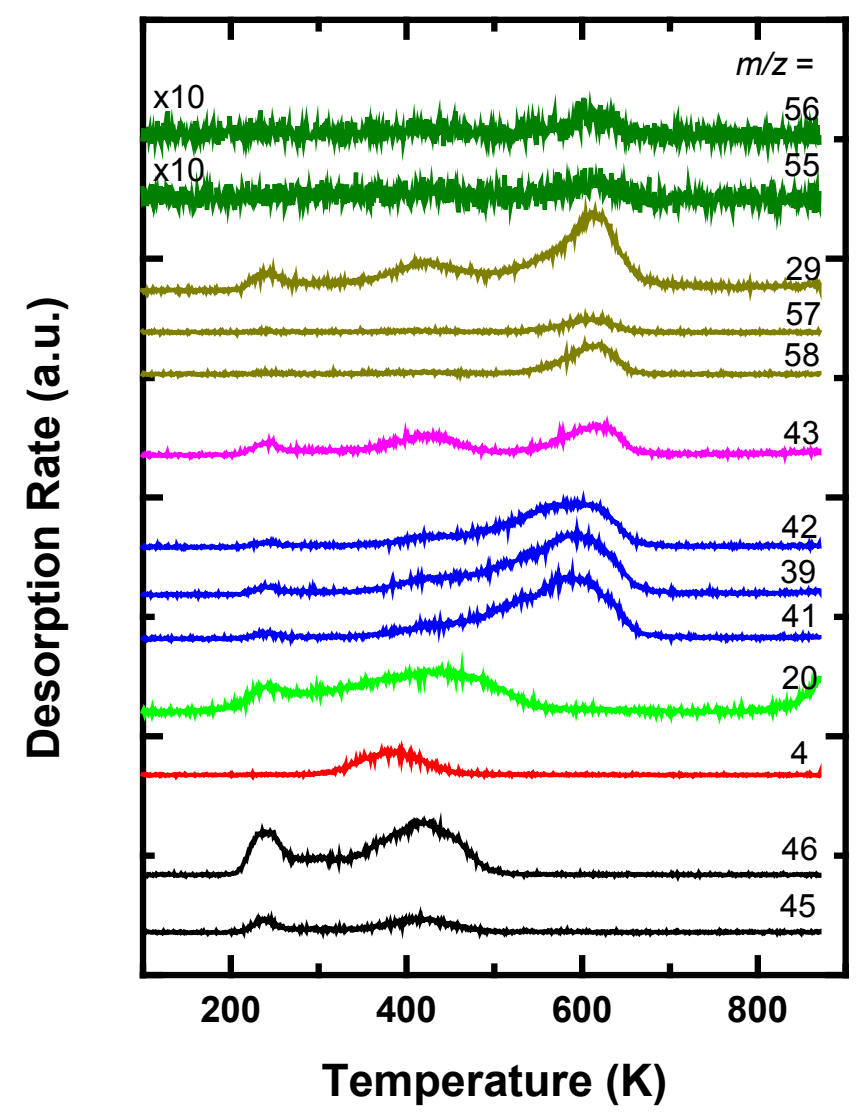

Figure S1. Set of TPD spectra with different mass fragments from the initial survey experiments obtained for $0.7 \mathrm{ML}$ of 1,2-PG, $\mathrm{DOCH}\left(\mathrm{CH}_{3}\right) \mathrm{CH}_{2} \mathrm{OD}$, on $r-\mathrm{TiO}_{2}(110)$ at $80 \mathrm{~K}$. 


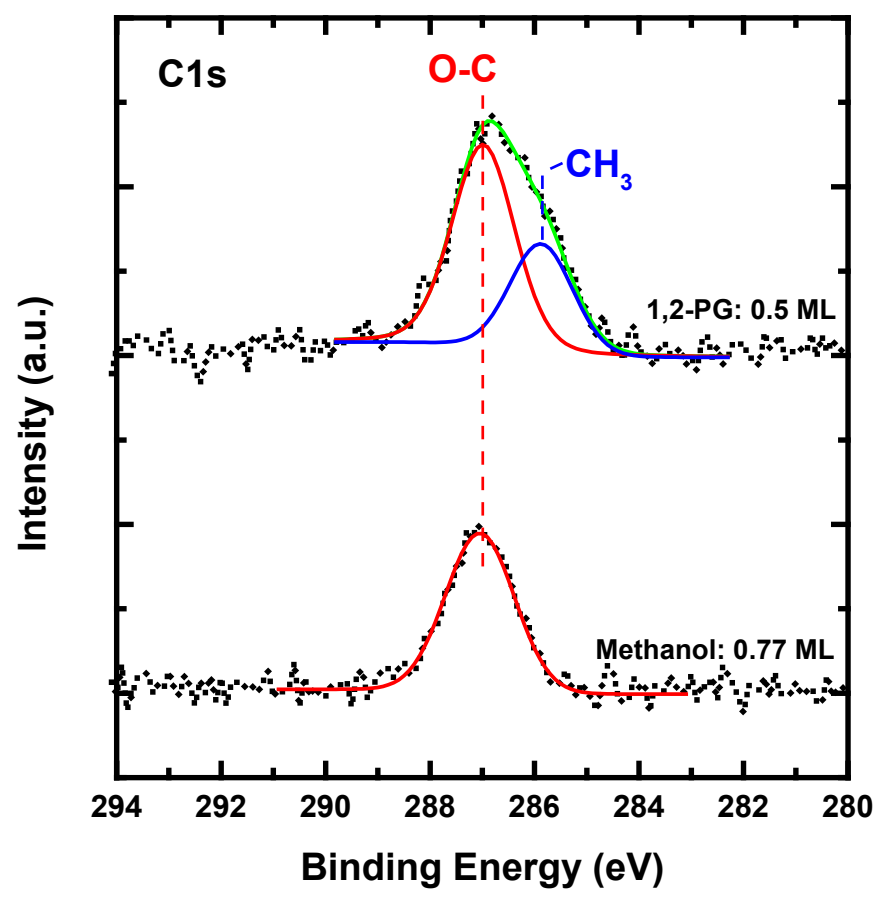

Figure S2. C1s XPS spectra for methanol and 1,2-PG adsorbed on $r-\mathrm{TiO}_{2}(110)$ at $80 \mathrm{~K}$. The coverages for both molecules were fixed at saturation coverage by accurately controlling the beam flux and coverage. The spectra were peak-fitted with the "XPS Peak" software (freeware). As expected, methanol has only one type of carbon (C-OH moiety), while 1,2-PG has two types of carbon $\left(\mathrm{C}-\mathrm{OH}\right.$ and $\mathrm{CH}_{3}$ moieties) that can be deconvoluted from the spectral envelopes. The component peaks at $\sim 287.0 \mathrm{eV}$ correspond to $\mathrm{C}-\mathrm{OH}$ moieties, and the peak at $\sim 285.6 \mathrm{eV}$ corresponds to the $-\mathrm{CH}_{3}$ moiety. The methanol saturation coverage on $\mathrm{Ti}_{5 \mathrm{c}}$ sites has been determined previously by QCM to be $0.77 \mathrm{ML} .{ }^{1}$ By normalizing the 1,2-PG C1s peak area to the methanol $\mathrm{C}$ 1s peak area, the saturation coverage of 1,2-PG on $\mathrm{Ti}_{5 \mathrm{c}}$ sites is calculated to be $0.5 \mathrm{ML}$.

\section{Reference}

1. Li, Z.; Smith, R. S.; Kay, B. D.; Dohnálek, Z. Determination of Absolute Coverages for Small Aliphatic Alcohols on $\mathrm{TiO}_{2}(110)$. J. Phys. Chem. C 2011, 115 (45), 22534-22539. 

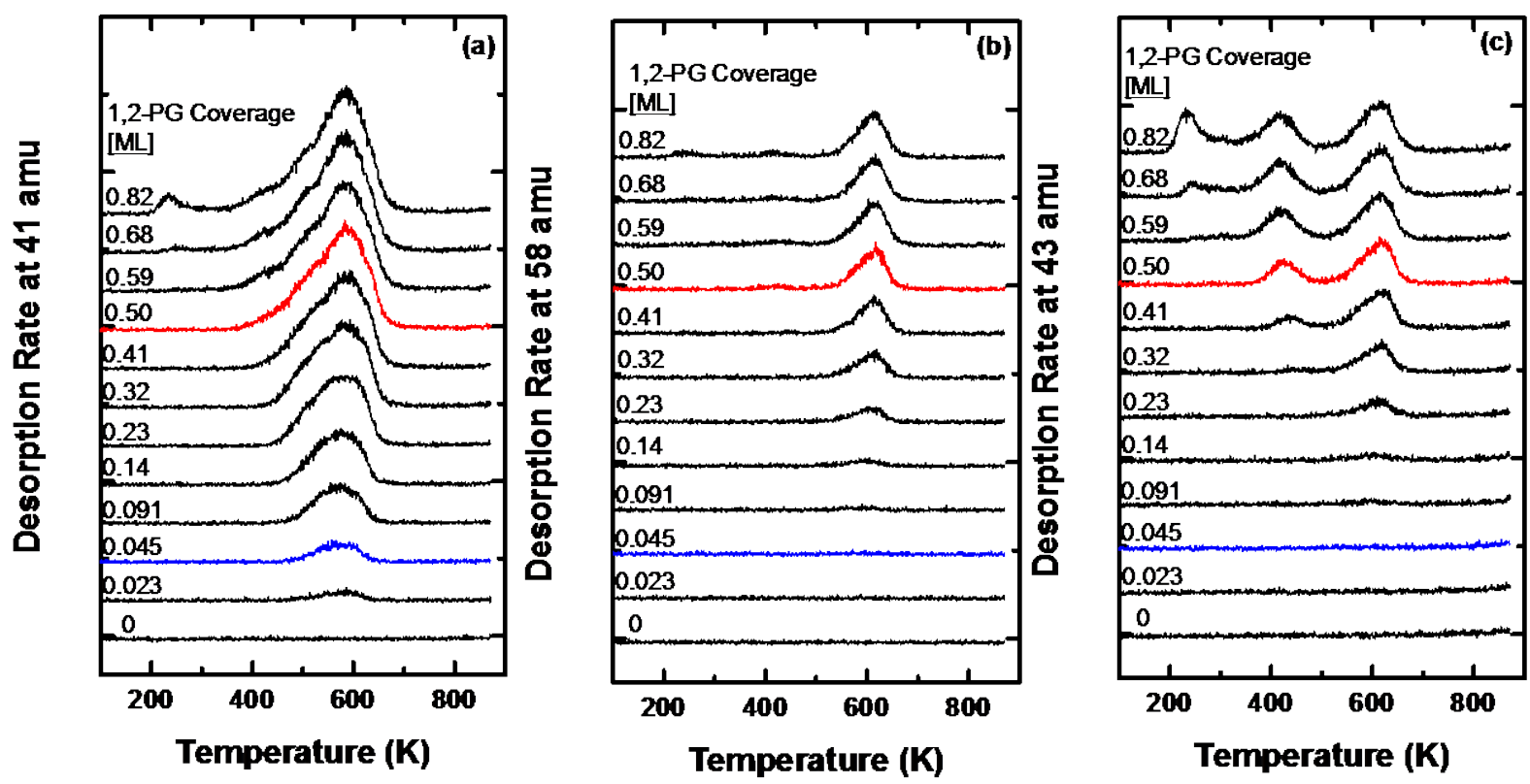

Figure S3. The unprocessed coverage dependent TPD spectra for (a) $\mathrm{CH}_{3} \mathrm{CH}=\mathrm{CH}_{2}$ obtained at $m / z=41 \mathrm{amu}$, (b) $\mathrm{CH}_{3} \mathrm{CH}_{2} \mathrm{CHO}$ at $58 \mathrm{amu}$, and (c) $\left(\mathrm{CH}_{3}\right)_{2} \mathrm{C}=\mathrm{O}$ at $43 \mathrm{amu}$. TPD traces for the 1,2-PG coverages that correspond to the $\mathrm{V}_{\mathrm{O}}$ concentration and $\mathrm{Ti}_{5 \mathrm{c}}$ saturation are highlighted with blue and red, respectively. 


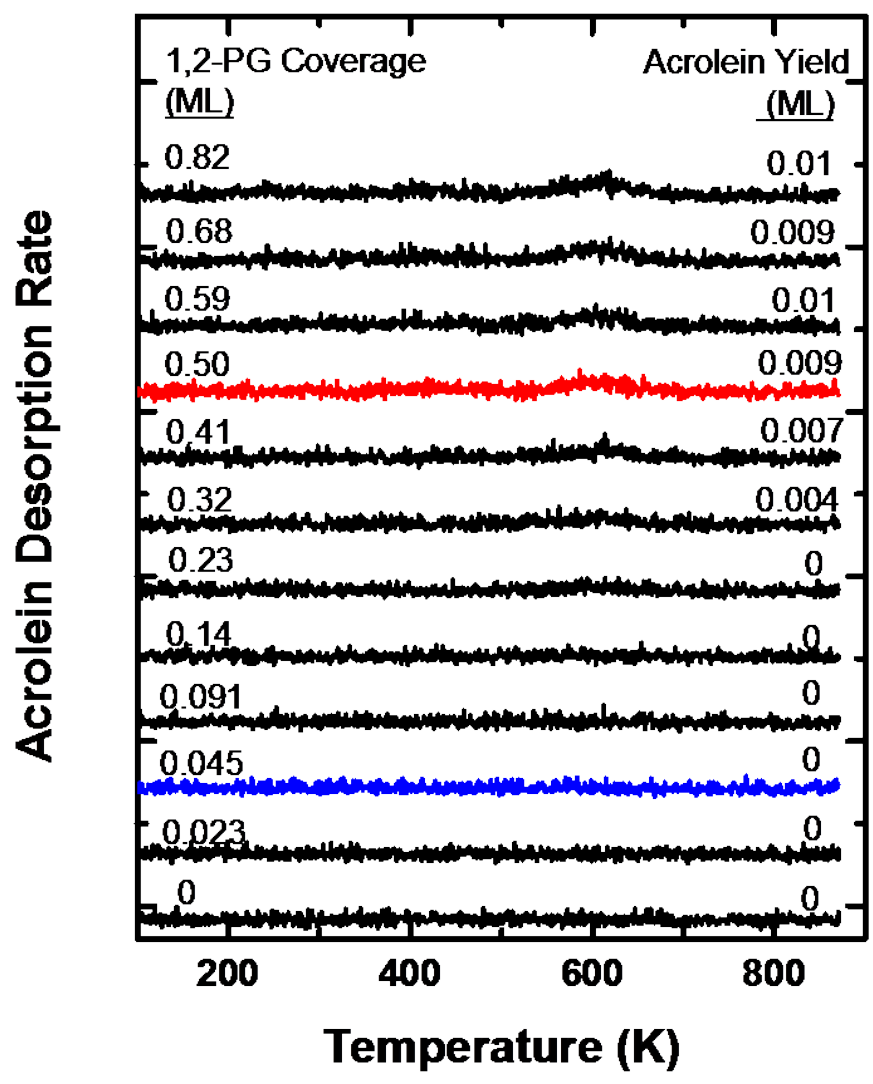

Figure S4. Coverage dependent TPD spectra of acrolein following 1,2-PG doses at $80 \mathrm{~K}$. The acrolein spectra were obtained using the $\mathrm{C}_{3} \mathrm{H}_{4} \mathrm{O}^{+}$mass fragment at $m / z=56$ amu. TPD traces for 1,2-PG coverages that correspond to the $\mathrm{V}_{\mathrm{O}}$ concentration and the saturation of $\mathrm{Ti}_{5 \mathrm{c}}$ sites are highlighted with blue and red, respectively. The integrated yields of desorbing acrolein are listed on the right side of the figure. 

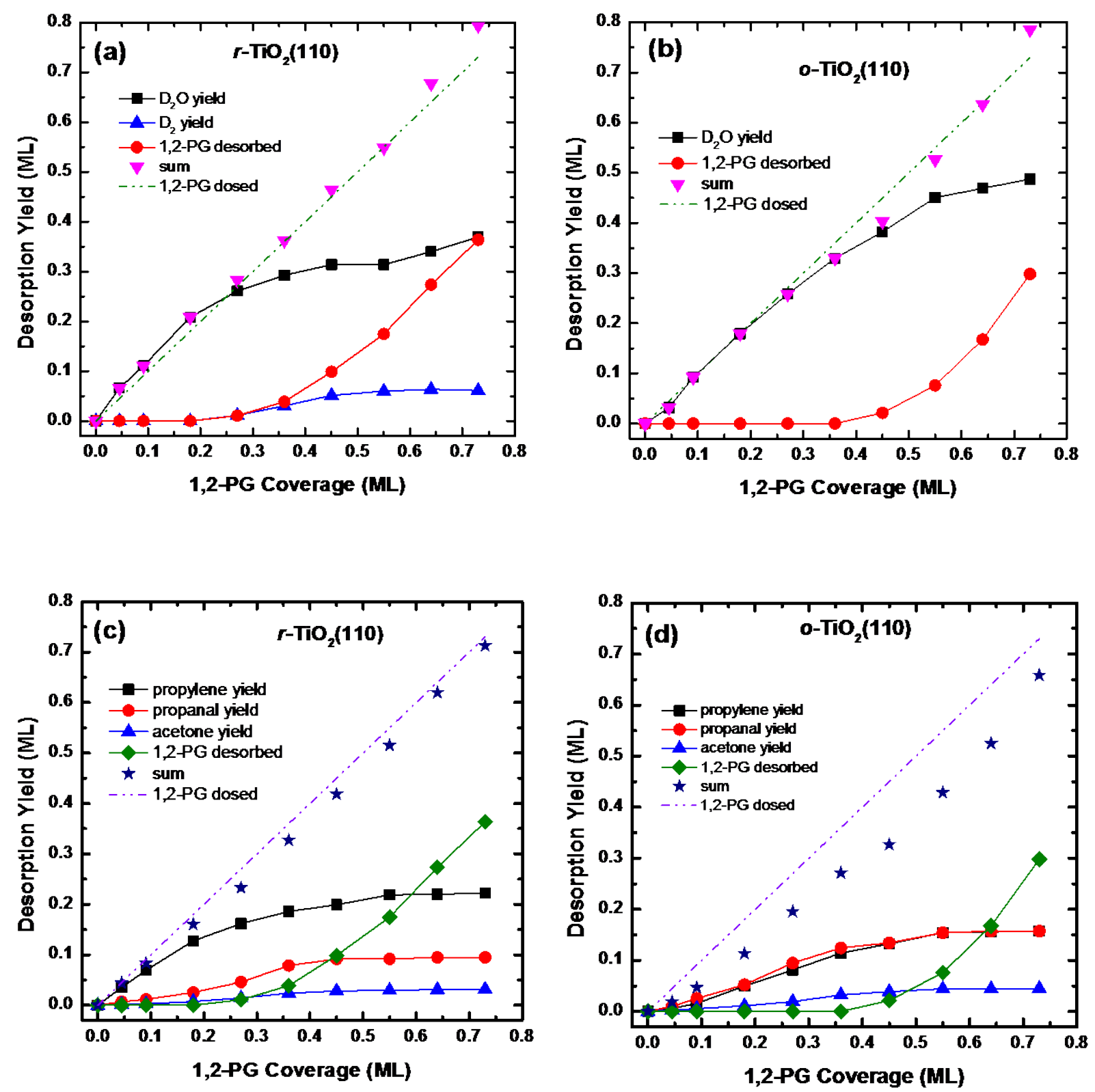

Figure S5. (a-b) Integrated amounts of desorbing $\mathrm{D}_{2} \mathrm{O}$ (black squares), $\mathrm{D}_{2}$ (blue triangles), 1,2PG (red circles) and their sum (magenta triangles) as a function of 1,2-PG coverage on (a) $r$ $\mathrm{TiO}_{2}(110)$ and (b) $o-\mathrm{TiO}_{2}(110)$. Short dash dot line represents the total amount of deuterium expected based on the 1,2-PG dose. (c-d) Integrated amounts of desorbing $\mathrm{CH}_{3} \mathrm{CH}=\mathrm{CH}_{2}$ (black squares), $\mathrm{CH}_{3} \mathrm{CH}_{2} \mathrm{CHO}$ (red circles), $\left(\mathrm{CH}_{3}\right)_{2} \mathrm{C}=\mathrm{O}$ (blue triangles), 1,2-PG (green diamonds) and their sum (navy stars) as a function of 1,2-PG coverage on (c) $r-\mathrm{TiO}_{2}(110)$ and (d) $o-\mathrm{TiO}_{2}(110)$. Short dash dot lines represent the total amount of carbon expected based on the 1,2-PG dose. 